\title{
Extreme midlatitude cyclones and their implications for precipitation and wind speed extremes in simulations of the Maunder Minimum versus present day conditions
}

\author{
C. C. Raible · M. Yoshimori $\cdot$ T. F. Stocker • \\ C. Casty
}

Received: 3 November 2005/ Accepted: 7 August 2006/Published online: 27 October 2006

(C) Springer-Verlag 2006

\begin{abstract}
Extreme midlatitude cyclone characteristics, precipitation, wind speed events, their inter-relationships, and the connection to large-scale atmospheric patterns are investigated in simulations of a prolonged cold period, known as the Maunder Minimum from 1640 to 1715 and compared with today. An ensemble of six simulations for the Maunder Minimum as well as a control simulation for perpetual 1990 conditions are carried out with a coupled atmosphere-ocean general circulation model, i.e., the Climate Community System Model (CCSM). The comparison of the simulations shows that in a climate state colder than today the occurrence of cyclones, the extreme events of precipitation and wind speed shift southward in all seasons in the North Atlantic and the North Pacific. The extremes of cyclone intensity increases significantly in winter in almost all regions, which is related to a stronger meridional temperature gradient and an increase in lower tropospheric baroclinicity. Extremes of cyclone intensity in subregions of the North Atlantic are related
\end{abstract}

C. C. Raible $(\bowtie) \cdot$ M. Yoshimori · T. F. Stocker •

C. Casty

Climate and Environmental Physics,

Physics Institute, University of Bern,

Sidlerstrasse 5, 3012 Bern, Switzerland

e-mail: raible@climate.unibe.ch

Present Address:

M. Yoshimori

Center for Environmental Prediction,

Rutgers University, 14 College Farm Road,

New Brunswick, NJ 08901-8551, USA

T. F. Stocker

International Pacific Research Center,

SOEST, University of Hawai'i, Honolulu, HI, USA to extremes in precipitation and in wind speed during winter. Moreover, extremes of cyclone intensity are also connected to distinct large-scale atmospheric patterns for the different subregions, but these relationships vanish during summer. Analyzing the mean $1,000 \mathrm{hPa}$ geopotential height change of the Maunder Minimum simulations compared with the control simulation, we find a similar pattern as the correlation pattern with the cyclone intensity index of the southern Europe cyclones. This illustrates that changes in the atmospheric high-frequency, i.e., the simulated southward shift of cyclones in the North Atlantic and the related increase of extreme precipitation and wind speed in particular in the Mediterranean in winter, are associated with large-scale atmospheric circulation changes.

\section{Introduction}

Climate mean has an imprint on society, but the society's sensitivity to climate extremes might be even more severe (Katz and Brown 1992). Destructive storms, like Lothar travelling over central Europe in December 1999, and flooding events, such as that of the river system Elbe in 2002 and the flooding of central Switzerland in 2005 show this in an arlarming manner. This series of extremes in the last decade has to be placed in a long-term perspective. As a further example of the past, the coastline of Germany underwent dramatic changes. The first "Marcellus flood" or "grosse Manndrenke" (the great man's drowning) in 1362 caused big land losses and the rich city Rungholt disappeared in the flooding. The second "grosse 
Manndrenke" (1634) changed the landscape primarily to the current coastline (Arends 1833). Another flooding in 1717, known as the "Christmas flooding", affected the entire coastline from the Netherlands up to Denmark with a loss of 12,000 human lives (Jakubowski-Tiessen 1992). Moreover, a proxy for storminess in winter shows that during the so-called "Little Ice Age" from the fourteenth to the nineteeth century more severe storms traveled over southern Scandinavia than today (Björck and Clemmensen 2004; De Jong et al. 2006). Therefore, the analysis of extremes comes more and more to the fore in climate research (Meehl et al. 2000).

Simulations with coupled general circulation models (GCMs) are a possibility to investigate extremes in the past, where no detailed observations exist. Moreover, GCM simulations have the advantage to generate several possible climate evolutions, leading to a great number of data, which is necessary to statistically analyze extremes. Previous studies demonstrate this ability mainly for scenario simulations. Recently, Schaeffer et al. (2005) showed in a modelling study of future projections for the A1B scenario (IPCC 2001) that changes in extreme temperature events could be even larger than expected on the basis of changes of the mean.

Besides temperature extremes, extreme weather events, such as storms, are one focus of climate research. Analyzing time slice experiments for present day and $2 \times \mathrm{CO}_{2}$, Beersma et al. (1997) found little impact on the storminess due to doubling of $\mathrm{CO}_{2}$. Similar to this study, Kharin and Zwiers (2000, 2005) again found little change in storminess and a small reduction of extreme wind speed in the North Atlantic region in an ensemble of coupled GCM simulations, but overall an increase in extreme precipitation almost everywhere on the globe. In contrast to this, some studies show an intensification of the midlatitude storms (Knippert et al. 2000; Leckebusch and Ulbrich 2004). These authors relate the increase of cyclone intensity to enhanced upper tropospheric baroclinicity. Recently, Fischer-Bruns et al. (2005) analyzed several multi-century preindustrial GCM simulations for the last millennium (González-Rouco et al. 2003; Zorita et al. 2004), concluding that the natural variability of storm activity is not related to solar, volcanic, and greenhouse gas (GHG) forcing nor to cold climate states, like the Maunder Minimum. But they found that in climate change experiments the storm frequency parallels the temperature increase, being in contrast to Kharin and Zwiers (2000), but resembling findings from, e.g., Leckebusch and Ulbrich (2004).
One test-bed to place recent modelling results concerning storminess in a long-term perspective is the "Little Ice Age", which spans the period from the fourteenth to the nineteenth centuries of colder conditions than today for the North-Atlantic-European region (Bradley and Jones 1993; Broecker 2000). The global extent of the "Little Ice Age" is still under debate (Bradley et al. 2003; Jones and Mann 2004). Embedded in this period is the so-called Maunder Minimum (1640-1715), defined by a period of reduced solar activity and a series of volcanic eruptions. The Maunder Minimum was subject to a number of studies. Temperature reconstructions show that the Maunder Minimum is a distinct and prolonged colder period on hemispheric scales than today (Jones et al. 1998; Mann et al. 1999; Esper et al. 2002). In modelling studies, Shindell et al. (2001) and Rind et al. (2004) showed that on regional scales the cooling is quite large, which could be traced back to a negative phase of the North Atlantic Oscillation (NAO). This phase shift was confirmed by reconstructions (Luterbacher et al. 2001, 2002). Casty et al. (2005b) and Raible et al. (2006) found in reconstructions an atmospheric regime shift to a more meridional atmospheric circulation, based on early measurements and documentary data. Moreover, there is evidence from documentary and proxy data that Maunder Minimum winters were wetter in southern Europe (Pauling et al. 2006).

Thus, our study focuses on simulated extremes of cyclone intensity, precipitation, and wind speed and their relationship to large-scale atmospheric patterns, comparing the Maunder Minimum with today. This gives us the possibility to relate our results with "observational" evidence, i.e., climate reconstructions. Therefore, we performed an ensemble of six Maunder Minimum simulations and a present day control simulation (Yoshimori et al. 2005, 2006), utilizing the Community Climate System Model (CCSM, Kiehl and Gent 2004). We will address the following questions:

- How do simulated mean characteristics of cyclones differ under colder climate conditions (Maunder Minimum) from today?

- Do extremes in cyclone intensity, precipitation, and wind speed change?

- Do extremes in cyclone intensity affect extremes in precipitation, and wind speed and, if so, was this relationship robust in the Maunder Minimum and today?

The outline of the paper is as followed: Sect. 2 introduces the model, the simulations, and analysis techniques. Then, cyclones are characterized by their mean cyclone density and their extreme intensity in 
Sect. 3. Extremes in precipitation and wind speed and their relationship to the extremes in intensity of cyclones are shown in Sect. 4. Finally, the results are summarized and conclusions are presented in Sect. 5 .

\section{Data and analysis techniques}

\subsection{Model and experimental setup}

To investigate the extremes of the Maunder Minimum, we use the CCSM version 2.0.1 developed by the National Center for Atmospheric Research (Kiehl and Gent 2004). The model consists of atmosphere, ocean, land surface, and sea ice components, coupled without flux corrections. We used the so-called paleo-resolution of the model, i.e., the atmospheric component with a horizontal resolution of T31 (approximately $3.75^{\circ} \times$ $3.75^{\circ}$ ) with $26 \sigma$-pressure vertical levels up to $2.6 \mathrm{hPa}$. The land component has the same horizontal resolution as the atmosphere. For the ocean the horizontal resolution is on average $3.6^{\circ}$ and $1.8^{\circ}$ in longitude and latitude. Vertically, 25 levels are used in the ocean model. The sea ice component is a dynamic-thermodynamic model, employing a subgrid-scale ice thickness distribution and elastic-viscous-plastic dynamics (Briegleb et al. 2004). It shares the horizontal resolution as the ocean component.

An ensemble of six transient Maunder Minimum simulations and a steady control simulation are carried out; details are given in Yoshimori et al. $(2005,2006)$. For the control simulation (CTRL) perpetual 1990 forcing is applied and 152 model years are used for the analysis. For the transient Maunder Minimum (TMM) simulations, a time-varying forcing from 1640 to 1715 , which includes the effect of solar activity and major volcanic eruptions, is applied. The volcanic forcing data are based on Crowley (2000); the solar forcing uses the data of Crowley (2000), scaled to the Maunder Minimum value in Lean et al. (1995). Both forcings are crudely represented as changes in total solar irradiance (hereafter TSI). The representation of the volcanic forcing in terms of TSI leads to uncertainties in the midand high-latitude winter responses of atmosphere modes. In particular, the role of the stratospheric ozone and the effect of volcanic aerosols, inducing a low-latitude stratospheric warming and positive annular mode in winters following an eruption (Haigh 1994; Shindell et al. 1999, 2001), are not included. The model simulations, however, show a similar, but weaker response of the annular mode in winter, but due to different reasons (Yoshimori et al. 2005). GHG concentrations are fixed at the level of 1640. For the six TMM ensemble mem- bers slightly different initial conditions are used from a perpetual 1640 simulation. More than $85 \%$ of the radiative forcing between the perpetual 1640 and 1990 CTRL simulations are due to GHG changes. Since the effect of time-varying forcing from 1640 to 1715 on the following results are much smaller than the effect of forcing between perpetual 1640 and 1990 CTRL, it is safe to assume that the difference (between TMM and 1990 CTRL) reflects primarily changes in GHG forcing and only to a smaller part changes in reduced solar and volcanic activity.

Due to the coarse resolution of the model the mean climate state of the CTRL and the TMM simulations shows some systematic deviations in the midlatitudes. The meridional overturning circulation (MOC) is in all simulations unrealistically weak $(\sim 8 \mathrm{~Sv})$. As a consequence the North Atlantic Drift as the northward extension of the Gulf Stream does not extend as far north as in observations and the sea ice edge of the North Atlantic is simulated too far south in the CTRL simulation. While simulated Atlantic thermohaline circulation is weak, the strength of wind-driven component of the subtropical gyre circulation in the North Atlantic is realistically reproduced. The maximum value of Sverdrup transport stream function is slightly larger than $30 \mathrm{~Sv}$ which is in good agreement with estimates based on observations (Böning et al. 1991; Wajsowicz 2002). Because of the fact that the MOC shows no changes between the CTRL and the TMM simulations, these systematic deviations are thought to be of minor relevance to the result of this study. Still, we have confidence in the simulations as Yoshimori et al. (2005) showed that the low-frequency temperature variations on a hemispheric scale agree with reconstructions (Jones et al. 1998; Mann et al. 1999). The simulations exhibit also a clear response to volcanic eruptions with positive North Atlantic Oscillation indices two years after eruptions. Again, this finding is resembled by proxy-based field reconstructions (Fischer et al. personal communication, Nov 2005). Despite this response to the volcanic forcing, the mean pressure behavior over the Maunder Minimum shows negative NAO indices in the TMM ensemble members, ranging from -0.17 to -0.44 [defined as in Hurrell (1995), but using the mean of 4 grid points of the 1,000 $\mathrm{hPa}$ geopotential height field nearby Iceland and the Azores]. This is in agreement with reconstructed NAO indices of -0.13 and -0.19 (Luterbacher et al. 2002; Cook et al. 2002), comparing the Maunder Minimum with the period 1950-2001. Additionally, the TMM simulations show a qualitatively similar response of the mean salinity changes in the tropical Pacific (Yoshimori et al. 2005), which were recorded in corals (Hendy et al. 2002). 


\subsection{Analysis methods}

To characterize midlatitude cyclones, a tracking scheme is used. Low pressure systems are identified as minima of the $1,000 \mathrm{hPa}$ geopotential height (halfdaily data) within a neighborhood of eight grid points. To neglect weak and unrealistic minima, a mean gradient of at least $20 \mathrm{gpm} / 1,000 \mathrm{~km}$ in a $1,000 \mathrm{~km}$ neighborhood is required. Furthermore, we require a minimum life-time of one day, and a minimum gradient of $30 \mathrm{gpm} / 1,000 \mathrm{~km}$ must be exceeded at least once during the life-cycle of the considered cyclone. The minima are then connected to cyclone trajectories by a next-neighborhood search within $1,000 \mathrm{~km}$. The cyclone density is defined as the occurrences per total number of observation times and area $\left(1,000^{2} \mathrm{~km}^{2}\right)$, but note that it does not include information about the strength of the cyclones. A minimum life-time of one day also guarantees that the life-cycle of a cyclone is included, that is, a deepening phase after the first occurrence, peaking after 48 hours in the mean, and a decline phase, where the cyclone is filled. The intensity of a cyclone is determined by the mean gradient of the $1,000 \mathrm{hPa}$ geopotential height around a detected minimum over $1,000 \mathrm{~km}$ for a certain time step. Note that the choice of the gradient is superior to other measures, e.g., central pressure, because the gradient is independent of the latitude. More details can be found in Blender et al. (1997) and Raible and Blender (2004).

To characterize extremes, the 90 percentile of the distribution of the cyclone intensity is estimated for all seasons and regions (Fig. 1), utilizing half-daily data. For example, the distribution of the mean gradient for one winter is estimated from $~ 900$ values of cyclone gradients in the North Atlantic. Note that $\sim 130 \mathrm{cy}-$ clones with an mean life-time of $\sim 7$ time steps $(\sim 80 \mathrm{~h})$ are found. The smaller the region, the less values are available to estimate the 90 percentile values, resulting in $~ 160$ values over Europe for one winter. For wind speed and precipitation, we estimate the distribution and its 90 percentile values from daily data.

The relation between the extreme cyclone intensity and the extreme behavior of precipitation and wind speed is illustrated by a correlation analysis. Therefore, we define indices of extreme cyclone intensity for all seasons [December-February (DJF); March-May (MAM); June-August (JJA); September-November (SON)] and in five different regions: North Atlantic, North Pacific, Europe, northern Europe, and southern Europe (Fig. 1).

The CTRL and TMM simulations are compared by showing differences TMM-CTRL. To test, if these differences are statistically significant at a level of $5 \%$,

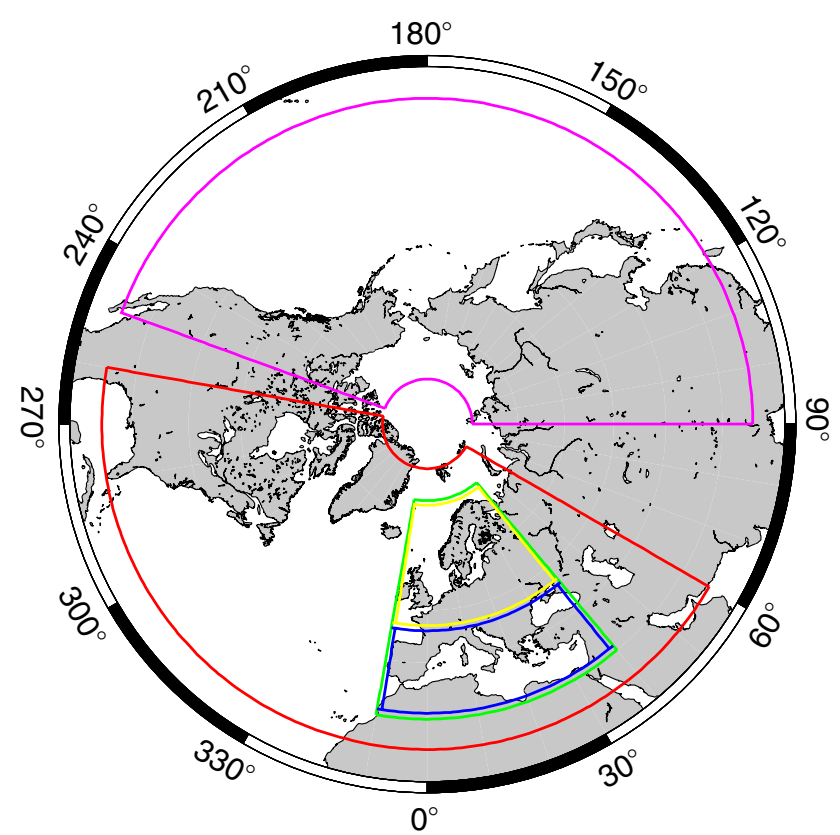

Fig. 1 The five regions chosen to define the cyclone intensity indices: North Atlantic (red), North Pacific (magenta), Europe (green), northern Europe (yellow), southern Europe (blue)

the Student's $t$ test or "Difference of Means Test" is applied. The means are estimated from the six TMM ensemble members and two independent CTRL phases of 76 years (from the 152 model years of the CTRL. Note also, that agreements and differences between the CTRL and reanalysis data (ERA-40, Simmons and Gibson 2000) are discussed.

\section{Mean and extreme cyclone characteristics}

Cyclones are characterized by two measures: the mean cyclone density and the cyclone intensity. The cyclone density of the CTRL resembles the observed patterns for all seasons (Fig. 2). In all seasons, two major cyclone track regions are found in the North Pacific and the North Atlantic with maxima near Kamchatka, the Aleutians, Newfoundland, and between Iceland and Scandinavia. The observed maximum over the Mediterranean as well as the absolute number of cyclones are underestimated in the CTRL simulation, due to the coarse model resolution (Blender and Schubert 2000). The seasonality of the cyclone density is reasonably reproduced as illustrated by the differences between winter and all other seasons, respectively. In spring, the cyclone density is increased in the genesis regions near Kamchatka and Newfoundland (Fig. 2b). The cyclone density shifts northwards in summer (Fig. 2c) compared with winter resembling observations (Sickmöller 
Fig. 2 Mean cyclone density [unit: \# cyclones/ $\left.\left(\operatorname{season}(1,000 \mathrm{~km})^{2}\right)\right]$ with a minimum life time of one day of the CTRL (mean over 152 model years): a DJF, b difference between MAM and DJF, $\mathbf{c}$ between JJA and DJF, and $\mathbf{d}$ SON and DJF
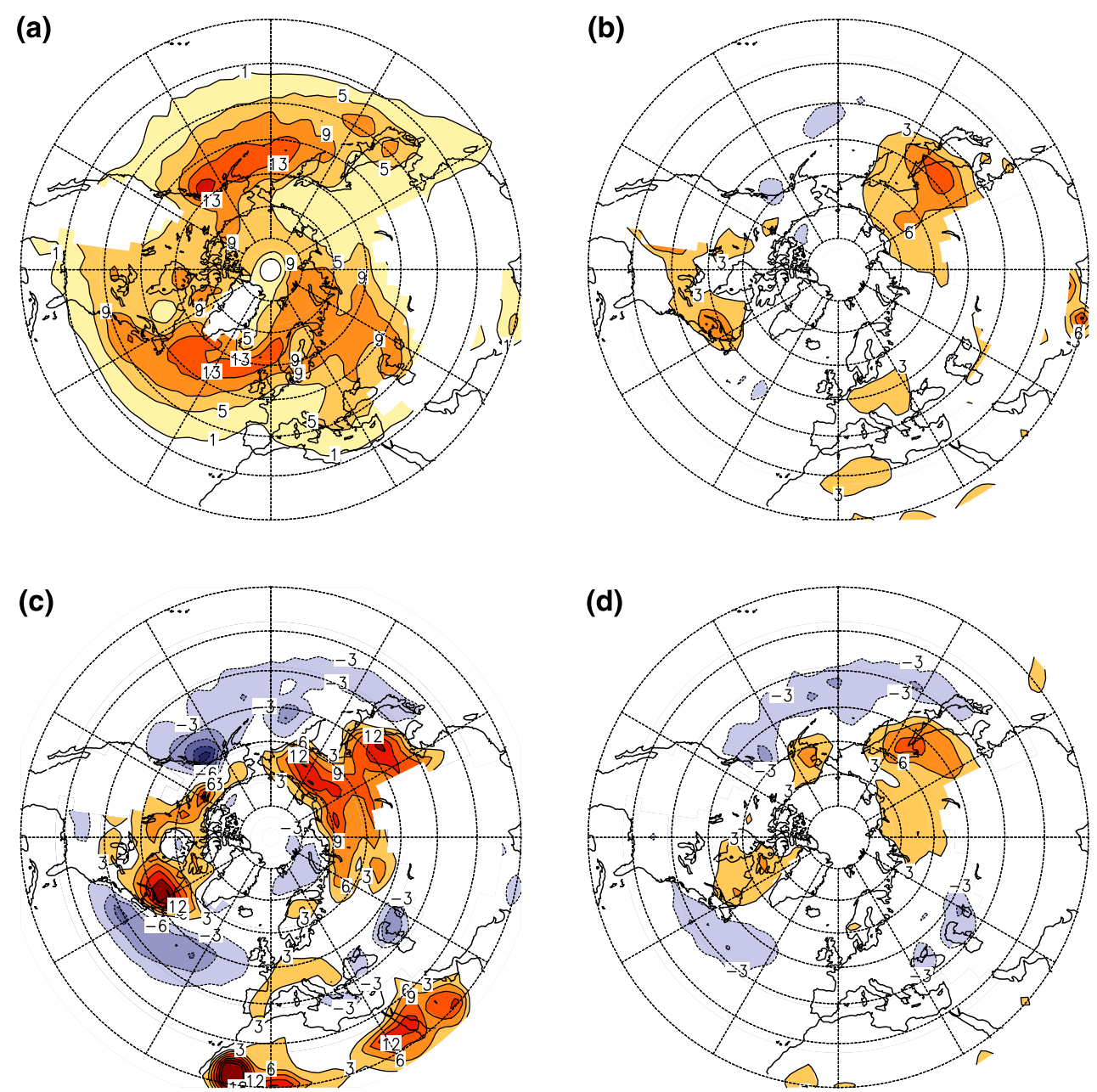

et al. 2000). This behavior is also found in autumn (Fig. 2d), but less pronounced, again resembling the observations.

The difference between the ensemble mean of the TMM and the CTRL shows significant changes in both major cyclone track areas (Fig. 3). In the North Pacific, a southward shift of the tail end of the cyclone track is found in winter (Fig. 3a) and less pronounced in the spring (Fig. 3b) and autumn (Fig. 3d). In summer, the North Pacific cyclone track is increased in its maximum areas (Fig. 3c), i.e., near Kamchatka and the Aleutians. In the North Atlantic, changes are stronger than in the North Pacific throughout the seasons. A reduction of cyclones is found north of $55^{\circ} \mathrm{N}$ and the number of cyclones increases south of $50^{\circ} \mathrm{N}$ in particular over Europe in all seasons and over the Mediterranean mainly in winter (Fig. 3a). Thus, cyclones are significantly redistributed in the Maunder Minimum compared with the CTRL, representing mean 1990 conditions. For Europe, this is in agreement with Luterbacher et al. (2001) who suggested a more southerly position of the mean polar front axes, which is connected with a negative NAO phase.

Cyclones are not only characterized by their frequency of occurrence (density), but also by their intensity, here measured by the mean gradient around a detected minimum. To focus on extremes, distributions of the cyclone intensity indices (defined in Sect. 2.2) are estimated. To illustrate this with an example, we show the histogram of the modeled 90 percentile mean gradients of cyclones in northern Europe for winter (Fig. 4). Compared with observations the model simulation exhibits weaker extremes of intensity because of the coarse resolution of the model (Blender and Schubert 2000). Figure 4 shows a clear shift to stronger gradients for northern Europe in the Maunder Minimum. The difference of mean of the distributions (TMM-CTRL) significantly changes by $+3.9 \mathrm{gpm} /$ $(1,000 \mathrm{~km})$. To illustrate the changes in the other regions and seasons in a comprehensive way, these mean differences are given in Table 1. Note, that using the median will not change the results. For all seasons and 
Fig. 3 Difference of the mean cyclone density [unit: \# cyclones/(season $\left.\left.(1,000 \mathrm{~km})^{2}\right)\right]$ with a minimum life time of 1 days between the ensemble mean of the TMM and the CTRL: a DJF, b MAM, c JJA, and d SON. Colors indicate positive (orange) and negative (blue) significant changes at a level of $5 \%$
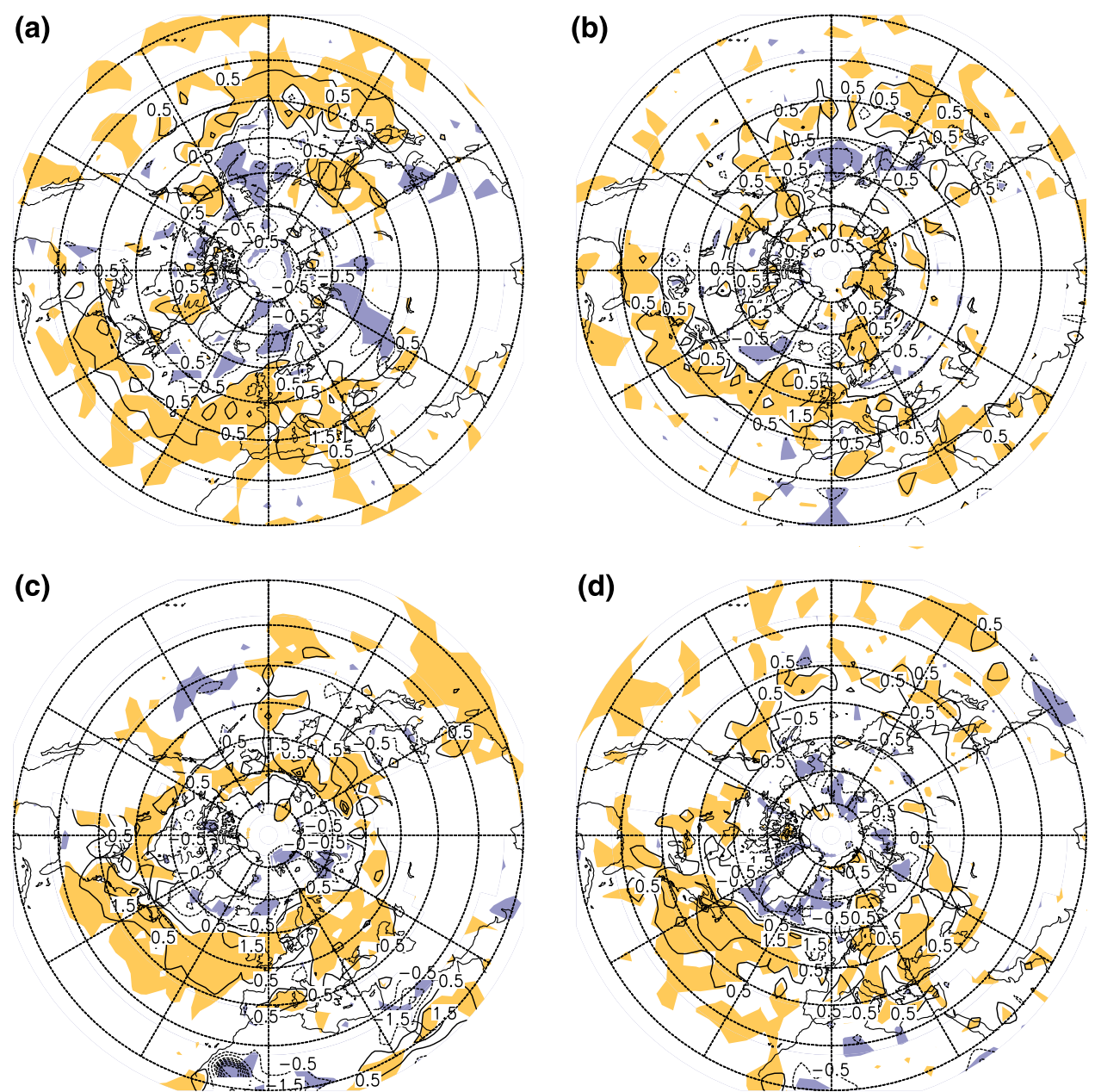

regions, a positive difference is found, i.e., the extreme cyclones intensify in the Maunder Minimum versus present day conditions. In winter the changes are significant at a level of $5 \%$ for all regions, except the North Pacific. The spring shows no significant changes, whereas summer exhibits significant changes in the North Atlantic and Europe. In autumn a significant intensification is found in the North Atlantic, southern Europe, and the Pacific, respectively. Note also that nearly all significant changes (using a Student's $t$ test) are confirmed by the fact that all individual changes between a certain ensemble member of TMM and the CTRL are positive.

One unexpected result is that, even though less cyclones are found in northern Europe, the intensity of the remaining extreme cyclones is increased. One reason for this could be that the simulated meridional temperature gradient in the TMM simulations is increased particularly in the North Atlantic region, where sea ice extends further south (illustrated by the winter temperature difference between TMM and
CTRL in Fig. 5). This has a direct impact on the baroclinicity defined by the maximum Eady growth rate $\sigma_{\mathrm{BI}}$ (Eady 1949; Lindzen and Farrell 1980; Lunkeit et al. 1998) at different levels (Fig. 6) with

$\sigma_{\mathrm{BI}}=0.31 \frac{1}{T}\left(\frac{1}{g \theta} \frac{\partial \theta}{\partial z}\right)^{-0.5}|\nabla T|$

where $g$ is the gravitational acceleration at sea level and $\theta$ the potential temperature. Below $500 \mathrm{hPa}$ a significant increase of the maximum Eady growth rate is found over central Europe and the Mediterranean and a strong reduction of baroclinicity over the area, where sea ice extends further south (between Scandinavia and Greenland). This is illustrated by the maximum Eady growth rate at $700 \mathrm{hPa}$ (Fig. 6a). The upper tropospheric baroclinicity in $300 \mathrm{hPa}$ is decreased except for a band between $45^{\circ} \mathrm{N}$ and $60^{\circ} \mathrm{N}$ in the North Atlantic European area and the North Pacific (Fig. 6b). Thus, the change of cyclone intensity seems to be related to the lower tropospheric baroclinicity 


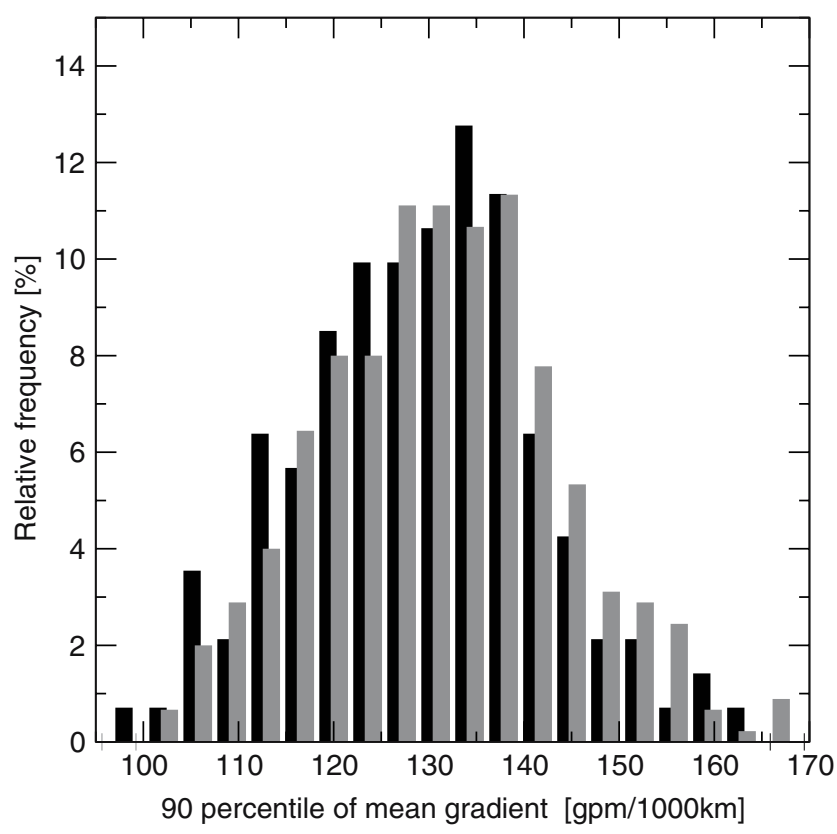

Fig. 4 The distribution of the 90 percentile values of cyclone intensity (unit: gpm per $1,000 \mathrm{~km}$ ) for cyclones in northern Europe (DJF): CTRL (black) and TMM (grey)

Table 1 Difference between the TMM and CTRL of the 90 percentile of the mean gradient $(\mathrm{gpm} / 1,000 \mathrm{~km})$ of cyclones with a minimum life-time of 1 day

\begin{tabular}{llllll}
\hline Season & Atlantic & Europe & N-Europe & S-Europe & Pacific \\
\hline DJF & $+\underline{\mathbf{1 . 8}}$ & $+\mathbf{2 . 7}$ & $+\underline{\mathbf{3 . 9}}$ & $+\underline{\mathbf{2 . 9}}$ & +0.2 \\
MAM & $+\overline{0.4}$ & +0.5 & $+\overline{0.8}$ & +1.2 & +0.4 \\
JJA & $+\underline{\mathbf{1 . 4}}$ & $+\underline{\mathbf{1 . 5}}$ & +1.2 & +0.2 & +1.5 \\
SON & $+\underline{\mathbf{1 . 4}}$ & $+\overline{0.4}$ & +0.2 & $+\underline{\mathbf{3 . 0}}$ & $+\mathbf{1 . 9}$ \\
\hline
\end{tabular}

Significant values at a level of $5 \%$ are highlighted in bold. Underlined values illustrate that all TMM ensemble members are individually higher than the CTRL mean

and not the upper tropospheric baroclinicity. Another possible important contribution, in generating intense cyclones, is the diabatic component of cyclones. The difference in latent heat flux between TMM and CTRL exhibits a reduction in the cyclone genesis regions close to Newfoundland, over areas where the sea ice extends further south, and over the continents (not shown). In the center area of storm activity (between Greenland and the British Islands), however, a significant increase of latent heat flux is simulated. This increase could contribute to the intensification of the cyclones in the Maunder Minimum in the Atlantic. But the contribution of the diabatic component seems to be small, because of the rather small increase and the strong reduction over the cyclone genesis regions. These changes of extremes in cyclone intensity should have

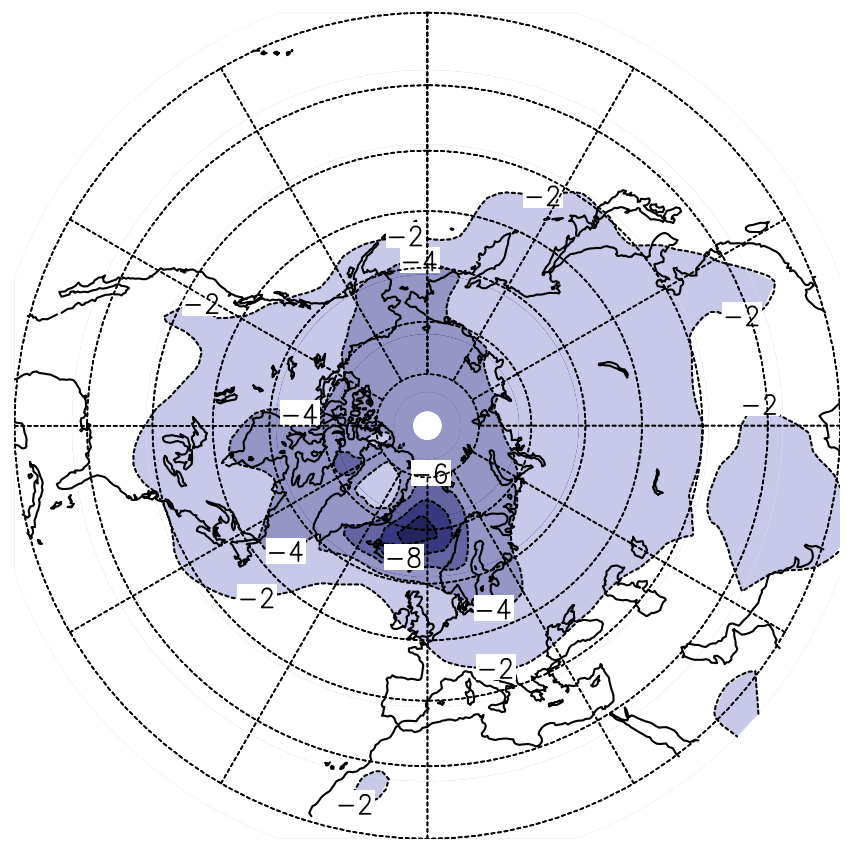

Fig. 5 Surface air temperature difference between TMM and the CTRL for winter (unit: K). Note that all differences are significant at a level of $5 \%$

implications on other climate relevant variables, e.g., extremes in precipitation and wind speed, which will be the focus in the next section.

\section{Implications for extreme precipitation, wind speed events and large-scale patterns}

In a first step the extreme behavior of precipitation and wind speed is analyzed. Both might be influenced by extremely strong cyclones. Therefore, we estimate the 90 percentile at each grid point of precipitation and wind speed fields, utilizing half-daily and daily data from the model, respectively. Comparing the TMM with the CTRL, this pattern of extremes in precipitation decreases in the polar region, whereas an increase of extreme precipitation events south of $\sim 45^{\circ} \mathrm{N}$ is found (Fig. 7). This is pronounced during winter (Fig. 7a), spring (Fig. 7b), and autumn (Fig. 7d) and appears to be of coherent spatial extent as the cyclone density (Fig. 7a, b, d). In summer the reduction of extreme precipitation is shifted northward (Fig. 7c) and the pattern is in general not so distinct as in winter. This again is consistent with the spatial changes of the cyclone density (Fig. 3c).

The 90 percentile of daily wind speed mainly shows significant changes in winter (Fig. 8a) and summer (Fig. 8c) with an increase of extreme wind speeds in the Mediterranean in winter and in a band from 20 to 

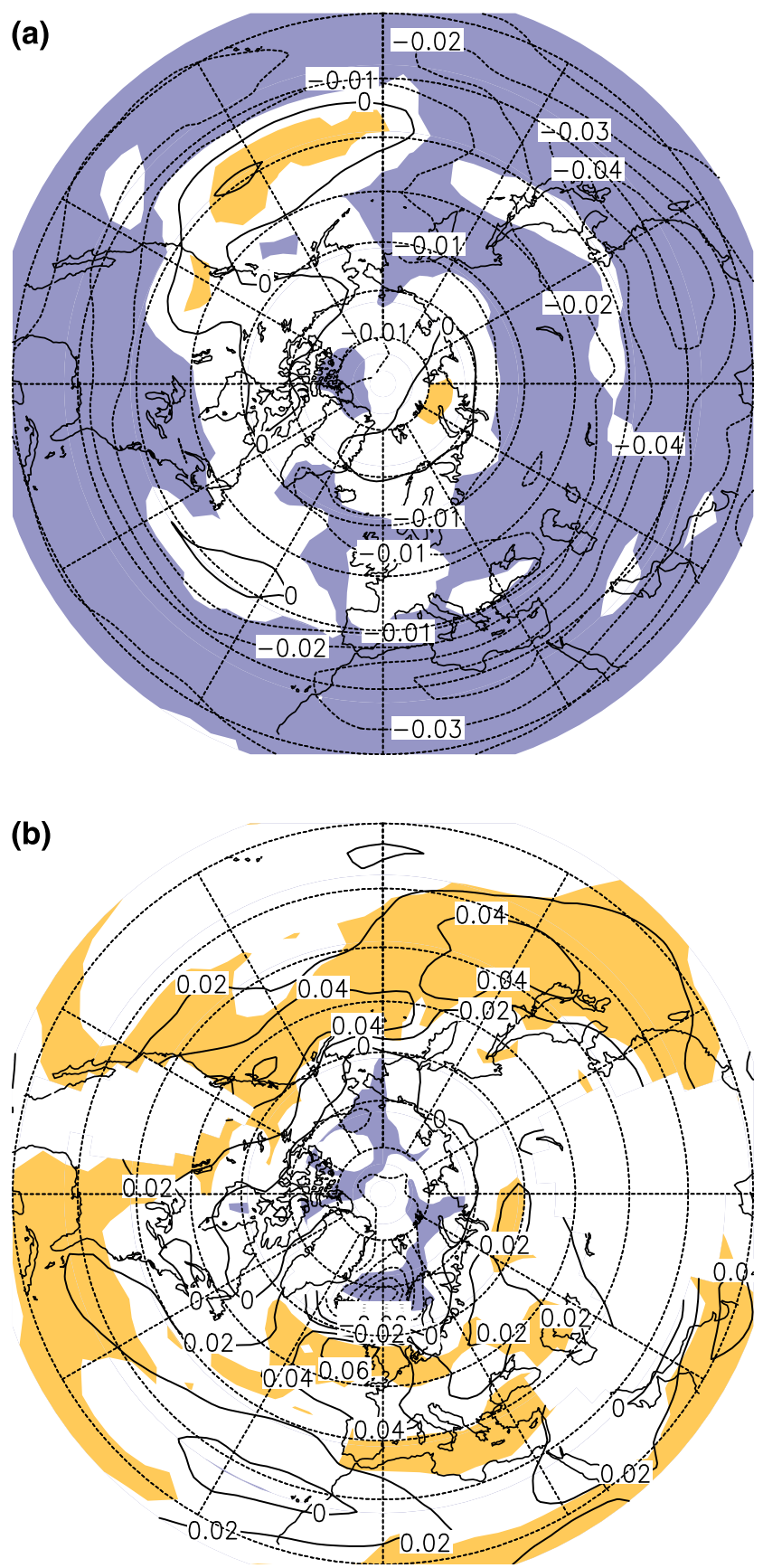

Fig. 6 Maximum Eady growth rate difference between TMM and the CTRL for winter (unit: 1/day): a $300 \mathrm{hPa}$ and b $700 \mathrm{hPa}$. Colors indicate positive (orange) and negative (blue) significant changes at a level of $5 \%$

$35^{\circ} \mathrm{N}$ over the oceans in summer. Again, one part of the changes seems to be related to the southward shift of the cyclone track. In spring (Fig. 8b) and autumn (Fig. 8d) changes in the extreme wind speed exhibit similar patterns as in winter, but these patterns are not significant.

Secondly, a correlation analysis is applied to the simulations to investigate the relationship between extreme cyclone intensity and extreme precipitation and wind speed in more detail. As the major changes occur during winter in the Atlantic region and the strongest seasonal signals occur in summer to winter comparisons, we focus on winter and summer for North Atlantic, northern, and southern Europe. Moreover, it turned out that the correlation patterns are unchanged in the TMM simulations compared with the CTRL, so the linear connections in the atmosphere between cyclones and atmospheric patterns seem to be independent of the mean climate. Thus we only present results of the CTRL.

The correlation between the extreme cyclone intensity index (90 percentile defined in Sect. 2.2) of the regions (North Atlantic, northern, and southern Europe) and the extreme precipitation and wind speed show remarkable patterns for DJF (Fig. 9). The correlation with the North Atlantic and northern Europe cyclone intensity index (Fig. 9a, c) exhibits a structure with increased extreme precipitation over the British Isles to Scandinavia and a decrease of extreme precipitation over southern Greenland and the Mediterranean, if the index is in its positive phase. Associated with this precipitation behavior, the pattern of extreme wind speed shows a strong increase over the central North Atlantic to the British Isles and a decrease over the Mediterranean (Fig. 9b, d). These simulated correlation patterns resemble the observation, using reanalysis data. The correlation patterns of the southern Europe cyclone intensity index behave differently (Fig. 9e, f). There, extreme precipitation is decreased between Iceland and Scandinavia, whereas it is increased over central Europe and the Mediterranean (Fig. 9e). The extreme wind speed shows a pronounced increase over the Mediterranean for the positive phase of the southern Europe cyclone intensity index (Fig. 9f). Note that the relationship between the southern Europe cyclone intensity index and extreme precipitation is not so clear in observations, whereas the extreme wind speed correlation pattern is similar to the observation. The winter relationships break down in summer, which is in agreement with observations.

Another open question is how these cyclone intensity indices are related to large-scale atmospheric patterns and the mean surface temperature? Therefore, the cyclone intensity indices are correlated with the 1,000 hPa geopotential height field and with the $2 \mathrm{~m}$ temperature. Note that the $2 \mathrm{~m}$ temperature is strongly related to the sea surface temperature over the oceans. In winter, we find again a strong connection to the large-scale circulation, illustrated by the $1,000 \mathrm{hPa}$ geopotential height field (Fig. 10, 
Fig. 7 Difference of 90 percentile of precipitation (unit: $\mathrm{mm} /$ day) between the ensemble mean of the six TMM simulations and the CTRL simulation: a DJF, b MAM, c JJA, and d SON. Colors indicate positive (green) and negative (yellow) significant changes at a level of $5 \%$
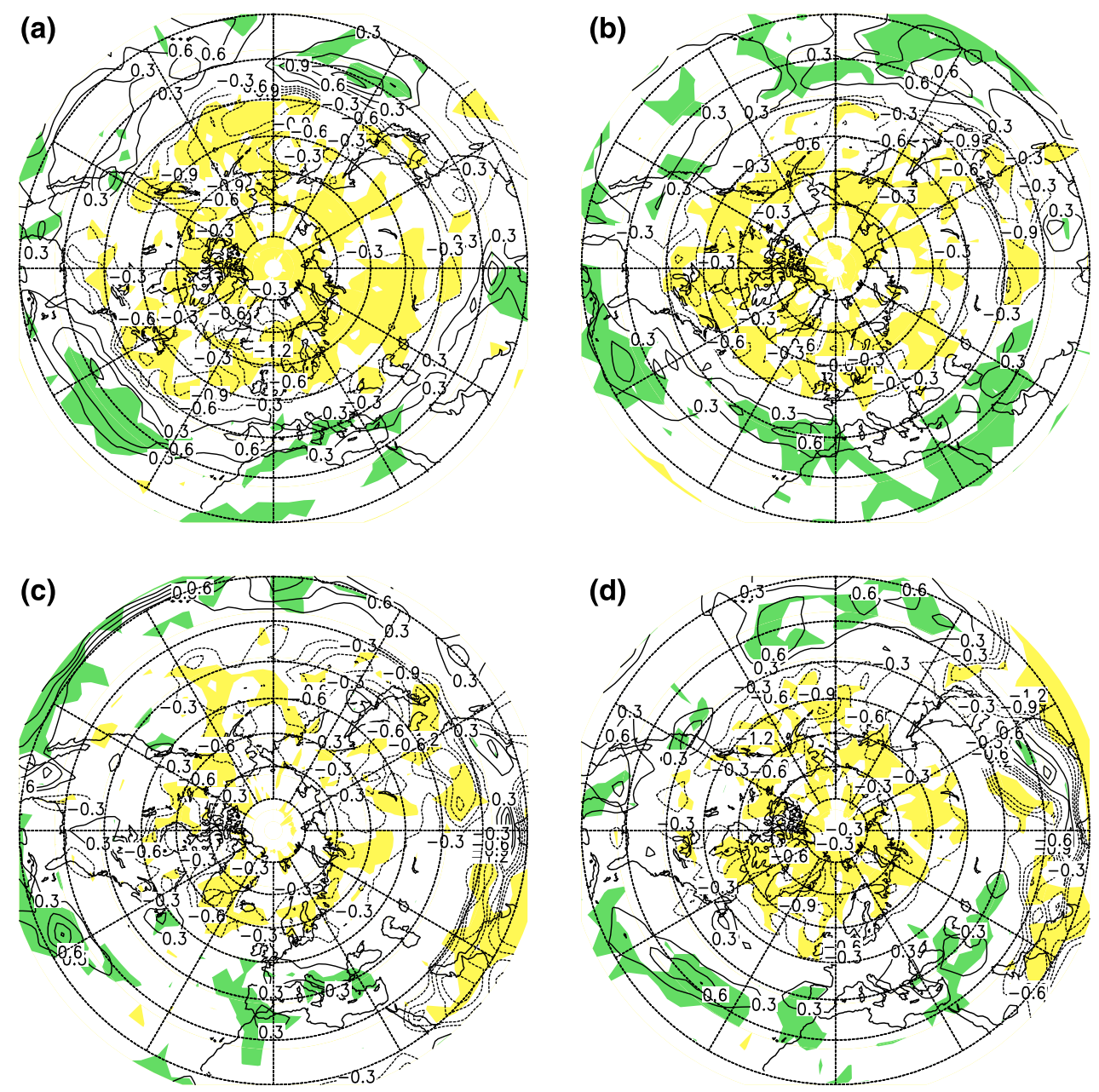

left) and the underlying surface air temperature (Fig. 10, right). For the North Atlantic (Fig. 10a) and the northern Europe cyclone intensity index (Fig. 10c) the circulation pattern exhibits positive correlations over the Mediterranean and negative over Iceland to Scandinavia, which is in agreement with observations. The surface air temperature correlation patterns go along with the circulation showing a warming over central and northern Europe and a cooling over Greenland and the eastern Mediterranean for the positive phase of both indices (Fig. 10b, d).

The correlation with the southern Europe cyclone intensity index for winter shows again a different pattern with a decrease over the Mediterranean and an increase between the British Isles and Iceland for a positive phase of the index (Fig. 10e). This correlation pattern is not so obvious in observations, where correlation coefficients are smaller. Again the surface air temperature correlation patterns (Fig. 10f) follows the circulation pattern with low temperatures over northern Europe and high temperatures over North Africa and the eastern part of the Mediterranean. The mean difference of the 1,000 hPa geopotential height field between the TMM and the CTRL in winter exhibits a similar structure (Fig. 11) as the correlation pattern of the southern Europe cyclone intensity index. Note that this mean difference is in good agreement with reconstructions (Luterbacher et al. 2002), showing positive geopotential height anomaly between Greenland an Iceland of $25 \mathrm{gpm}$ and negative one of $-15 \mathrm{gpm}$ over southern Europe and the Mediterranean. This partly explains the southward shift of the mean cyclone density (Fig. 3a) and extreme precipitation (Fig. 7a) and the increase in extreme wind speed over the Mediterranean (Fig. 8a). Note that Fig. 11 represents the long-term mean difference, which gives little information about the variance or the extreme behavior, so no straightforward implications on the cyclone intensity could be derived from this figure. In summer, the correlations between the indices and the largescale circulation and the temperature vanish as for the extremes in precipitation and wind speed (not shown). 
Fig. 8 Difference of 90 percentile of the $1,000 \mathrm{hPa}$ wind speed $\left(\sqrt{u^{2}+v^{2}}\right.$ with $u$ zonal wind in $1,000 \mathrm{hPa}$ and $v$ meridional wind in $1,000 \mathrm{hPa}$; unit: $\mathrm{m} / \mathrm{s}$ ) between the ensemble mean of the six TMM simulations and the CTRL simulation: a DJF, b MAM, c JJA, and d SON. Colors indicate positive (orange) and negative (blue) significant changes at a level of $5 \%$. Note that all areas exceeding $1,000 \mathrm{~m}$ of altitude are excluded due to extrapolation
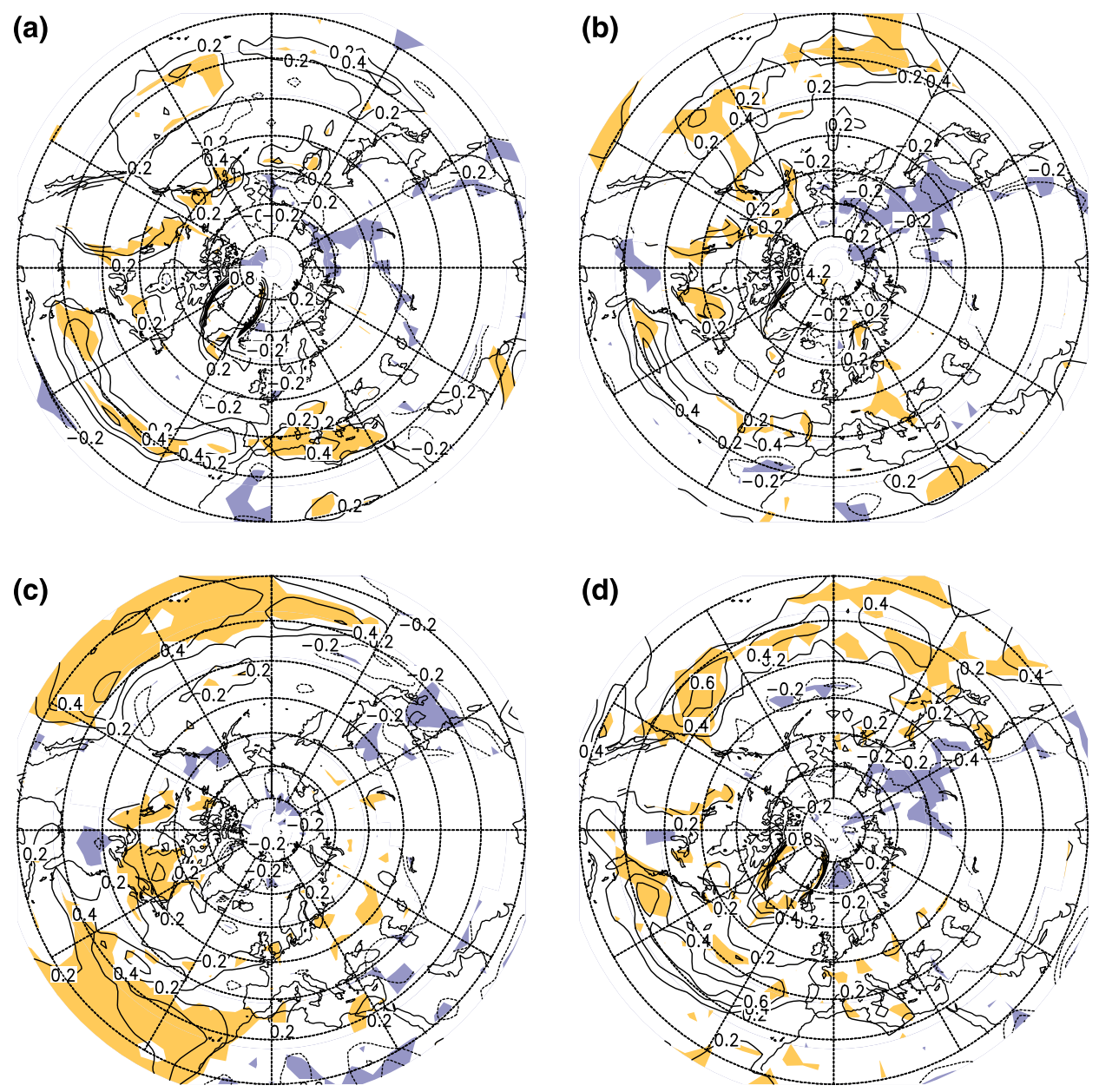

\section{Summary and conclusions}

An ensemble of Maunder Minimum simulations is compared with a 1990 control simulation with respect to extremes in midlatitude cyclone characteristics, precipitation, and wind speed. The relation between extreme cyclone intensity and extremes in precipitation and wind speed as well as the connection to large-scale atmospheric patterns are presented. The simulations are performed with the coupled atmosphere-ocean GCM CCSM2.

Comparing the Maunder Minimum simulations with the 1990 control simulation, we found that the cyclone density, i.e., the occurrences of cyclones, significantly decreases in the polar area whereas more cyclones are simulated south of $50^{\circ} \mathrm{N}$, in particular in the Mediterranean in all seasons for the Maunder Minimum. Simultaneously, extreme precipitation is reduced in the polar area and enhanced south of $\sim 45^{\circ} \mathrm{N}$ in all seasons. Extreme wind speed events are intensified in winter and summer in similar areas as the extreme precipitation and the mean cyclone density.
But not only the cyclone density is changed in a colder than today climate. Extremes of cyclone intensity are significantly stronger in the Maunder Minimum compared with the 1990 control simulation in the whole North Atlantic and also in subregions of the North Atlantic in particular in winter. This increase in extreme cyclone intensity is related to a stronger meridional temperature gradient, producing an increase of lower tropospheric baroclinicity over central Atlantic to Europe and a decrease over areas, where the sea ice grows further south (between Scandinavia and Greenland). The upper tropospheric baroclinicity remains unchanged between 45 and $60^{\circ} \mathrm{N}$ in the North Atlantic European area and the North Pacific and is decreased south of $45^{\circ} \mathrm{N}$. The diabatic component of cyclones plays a minor role in the intensification, showing a small but significant increase of latent heat flux in the central Atlantic and a decrease in the genesis regions of the cyclones. Thus, we conclude that mainly the temperature gradient and the lower tropospheric baroclinicity helps in the intensification of extreme cyclones in the Maunder Minimum simulations. 
Fig. 9 Correlation pattern of the cyclone intensity indices with extreme precipitation (left panels) and extreme wind speed (right panels) for DJF in the CTRL: a, b North Atlantic index, $\mathbf{c}, \mathbf{d}$ northern Europe, and $\mathbf{e}, \mathbf{f}$ southern Europe. Shading increment is 0.1 starting with -0.2 and +0.2
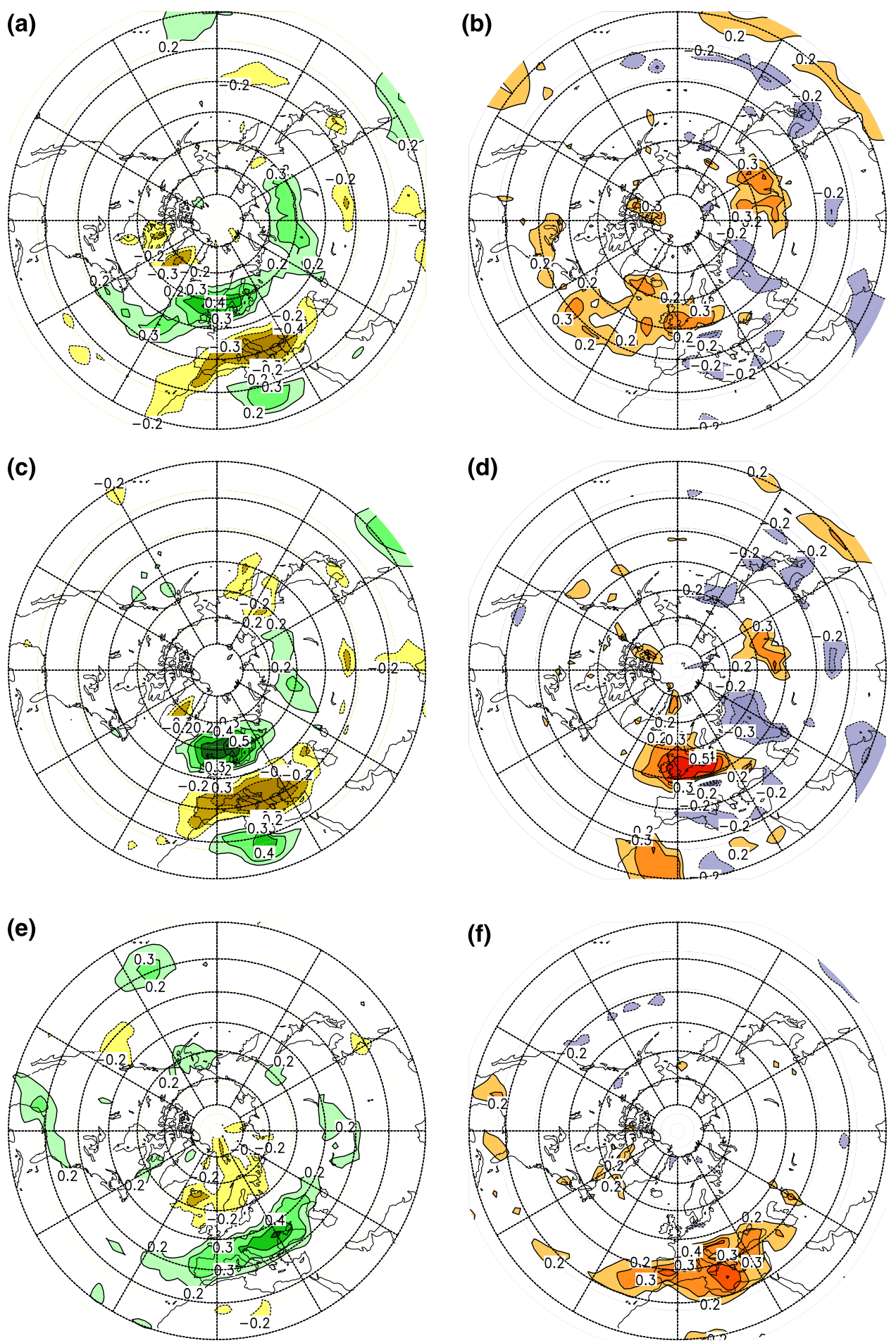

The correlation analysis, using cyclone intensity indices for different regions, gives some information about the relationship between extreme cyclone intensity and precipitation, wind speed, and the atmospheric large-scale circulation. In winter, distinct correlation patterns are found. A positive cyclone intensity index in the Atlantic or the northern Europe is related to reduced precipitation and wind speed extremes over the Mediterranean and stronger precipitation and wind speed extremes over northern Europe. The large-scale circulation illustrated by the correlation with the 1,000 hPa geopotential height field shows 
Fig. 10 Correlation pattern of the cyclone intensity indices with $1,000 \mathrm{hPa}$ geopotential height (left panels) and $2 \mathrm{~m}$ temperature (right panels) for DJF in the CTRL: a, b North Atlantic index, c, d northern Europe, and $\mathbf{e}, \mathbf{f}$ southern Europe. Shading increment is 0.1 starting with -0.2 and +0.2
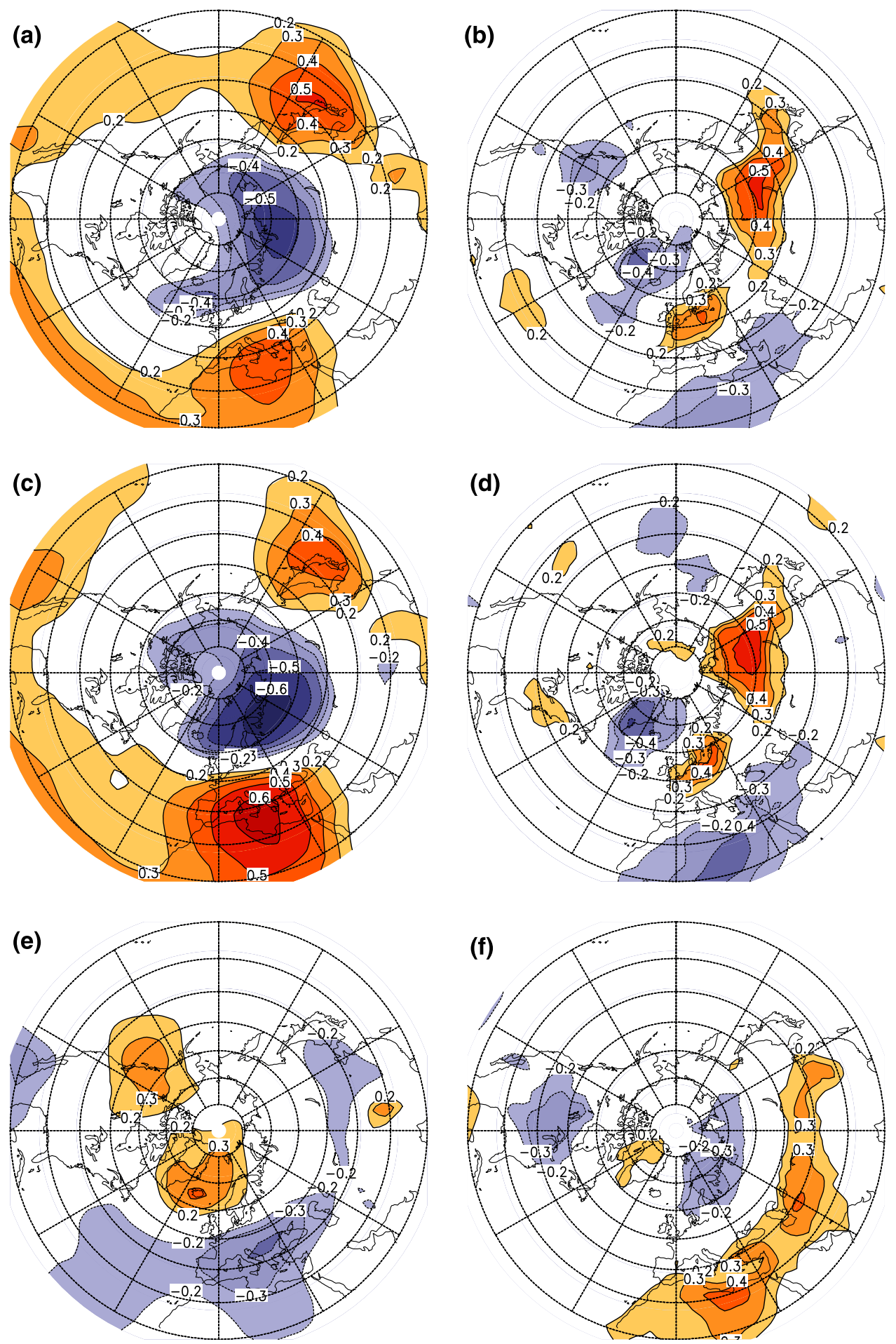

a NAO-like pattern, but shifted eastwards. The correlation patterns with the southern Europe cyclone intensity index differ, showing an increase in extreme precipitation and wind speed over southern Europe and the Mediterranean for the positive phase of the index. This is related to a negative NAO-like large- scale circulation pattern with negative geopotential height anomalies over the Mediterranean and positive ones between Greenland and Scandinavia. A similar circulation pattern is also found by comparing the mean $1,000 \mathrm{hPa}$ geopotential height field of the Maunder Minimum simulations with the 1990 control 


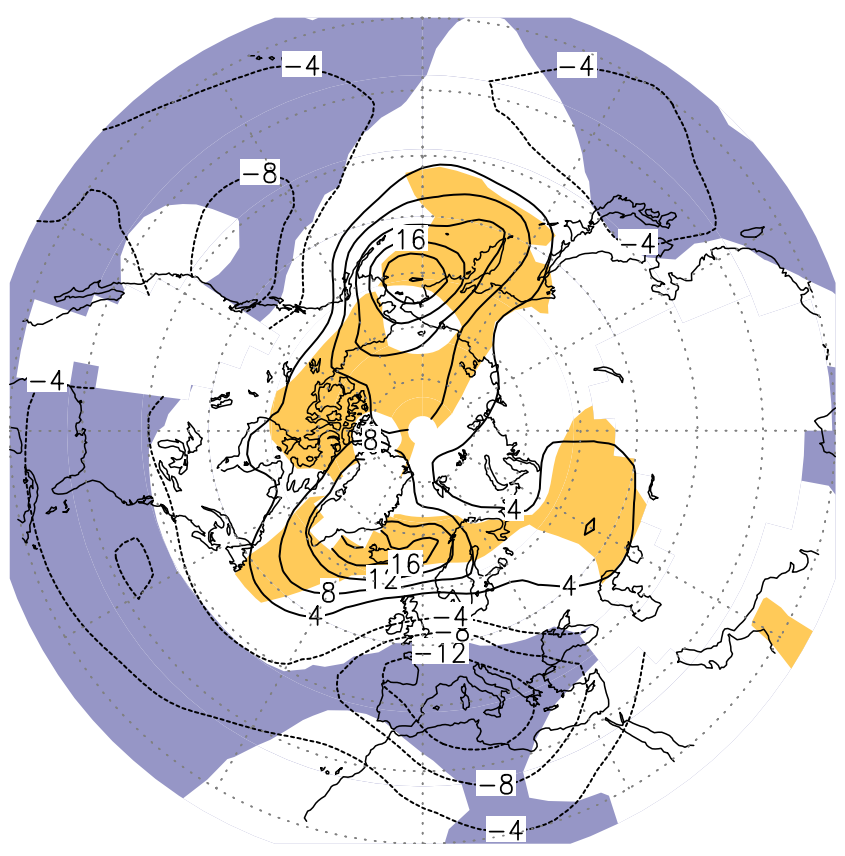

Fig. 11 1,000 hPa geopotential height difference between TMM and the CTRL for winter. Colors indicate positive (orange) and negative (blue) significant changes at a level of $5 \%$. Note that all areas exceeding $1,000 \mathrm{~m}$ of altitude are excluded due to extrapolation

simulation. Thus, in winter we conclude that the atmospheric high-frequency behavior in the Mediterranean, illustrated by the cyclone characteristics, is associated with large-scale atmospheric circulation changes. In summer, these relationships disappear, leading to the conclusion that other processes than cyclones, e.g., convective events, are probably more important for extreme precipitation. This is in good agreement with findings of Schär et al. (2004).

The comparison of our results with other studies exhibits a mixed picture. The southward shift of cyclones tracks is consistent with climate change studies (Yin 2005; Bengtsson et al. 2006), if we assume a linear response of extremes in cyclones between warm and cold climate. Another modelling study (Fischer-Bruns et al. 2005) concludes that cyclone characteristics are decoupled from temperature and not related to external forcing, i.e., the sun, volcanos and GHG, which is in contrast to our findings. However, there are implications from documentary data (e.g., Jakubowski-Tiessen 1992) and reconstructions that storms were more severe in the past than today. During the Little Ice Age a winter proxy for storminess shows more severe storms traveling over southern Scandinavia than today (Björck and Clemmensen 2004). Using reconstructed precipitation fields over land for the last 500 years, Pauling et al. (2006) found that at least the mean winter precipitation was increased in southern Europe and decreased in northern Europe during the Maunder Minimum. Casty et al. (2005a) and Raible et al. (2006) showed in reconstructions that this precipitation pattern is connected with a blocking-like circulation pattern similar to our findings. Moreover, reconstructions (Cook et al. 2002; Luterbacher et al. 2001, 2002) showed that the mean of the NAO index was negative during the Maunder Minimum, which is another hint of the more frequent blocking-like circulation patterns. Thus, our modelling results, i.e., the intensification of extremes in cyclones and the increase of precipitation extremes in the Mediterranean in the Maunder Minimum, is consistent with these documentary and proxy data.

However, one limitation of our study is the fact that only one model is used. Thus, the interpretation is restricted to the confidence we have in this particular model and its sub-grid parameterizations, which are obviously important to produce extremes. One way forward would be to analyze a multi-model ensemble for past climate simulations similar to the approach of Yin (2005). It has also implications for studies of future scenarios showing that the projections of midlatitude cyclone behavior should be placed in a longer term context.

Acknowledgments We thank Guido Poliwoda for the historical references. This work is supported by the National Centre for Competence in Research (NCCR) on Climate funded by the Swiss National Science Foundation. Simulations are carried out at the Swiss National Computing Centre in Manno, Switzerland. $\mathrm{CC}$ is supported by the European Project entitled "Patterns of Climate Variability in the North Atlantic (PACLIVA, EVR12002-000413)". This is IPRC contribution \# 389. TFS is partially supported by the IPRC Visitor Program. ERA-40 reanalysis data were provided by European Centre for Medium-Range Weather Forecasts (http://www.data.ecmwf.int/data/index.html).

\section{References}

Arends F (1833) Physische Geschichte der Nordseeküste und deren Veränderungen durch Sturmfluthen seit der Cymbrischen Fluth bis jetzt. Emden, Germany

Beersma JJ, Rider KM, Komen GJ, Kaas E, Kharin V (1997) An analysis of extra-tropical storms in the North Atlantic region as simulated in a control and $2 \times \mathrm{CO}_{2}$ time-slice experiment with a high-resolution atmospheric model. Tellus 49:347361

Bengtsson L, Hodges KI, Roeckner E (2006) Storm tracks and climate change. J Clim 19:3518-3543

Björck S, Clemmensen LB (2004) Aeolian sediment in raised bog deposits, Halland, SW Sweden: A new proxy record of Holocene winter storminess variation in southern Scandinavia. Holocene 14:677-688

Blender R, Schubert M (2000) Cyclone tracking in different spatial and temporal resolutions. Mon Wea Rev 128:377384 
Blender R, Fraedrich K, Lunkeit F (1997) Identification of cyclone-track regimes in the North Atlantic. Q J Roy Meteor Soc 123:727-741

Böning CW, Döscher R, Isemer HJ (1991) Monthly mean wind stress and Sverdrup transports in the North Atlantic: a comparison of Hellerman-Rosenstein and Isemer-Hasse Climatologies. J Phys Ocean 21:221-235

Bradley RS, Jones PD (1993) 'Little Ice Age' summer temperature variations: their nature and relevance to recent global warming. Holocene 3:367-376

Bradley RS, Briffa KR, Cole J, Hughes MK, Osborn TJ (2003) The climate of the last millennium. In: Alverson K, Bradley RS, Pedersen TF (eds) Paleoclimate, global change, and future. Springer, Berlin Heidelberg New York, pp 105-141

Briegleb BP, Bitz CM, Hunke EC, Lipscomb WH, Holland MM, Schramm JL, Moritz RE (2004) Scientific description of the sea ice component in the community climate system model, Version 3, National Center for Atmospheric Research, Boulder, CO.80307-3000, Tech. Report, 77pp

Broecker WS (2000) Was a change in the thermohaline circulation responsible for Little Ice Age? Proc Nat Acad Sci USA 97:1339-1342

Casty C, Handorf D, Raible CC, Luterbacher J, Weisheimer A, Xoplaki E, González-Rouco JF, Dethloff K, Wanner H (2005a) Recurrent climate winter regimes in reconstructed and modelled $500 \mathrm{hPa}$ geopotential height fields over the North Atlantic-European sector 1659-1990. Clim Dynam 24:809-822. DOI 10.1007/s00382-004-0496-8

Casty C, Handorf D, Sempf M (2005b) Combined winter climate regimes over the North Atlantic/European sector 17662000. Geophys Res Lett 32. DOI 10.1029/2005GL022431

Cook ER, D'Arrigo RD, Mann ME (2002) A well-verified, multiproxy reconstruction of the winter North Atlantic Oscillation index since A.D. 1400. J Clim 15:1754-1764

Crowley TJ (2000) Causes of climate change over the past 1000 years. Science 289:270-277

De Jong R, Björck S, Björkman L, Clemmensen LB (2006) Storminess variations during the last 6500 years as reconstructed from and ombrotrophic bog in Halland, SW Sweden. J Quat Science (in press)

Eady ET (1949) Long waves and cyclone waves. Tellus 1:33-52

Esper J, Cook ER, Schweingruber FH (2002) Low-frequency signals in long tree-ring chronologies for reconstructing past temperature variability. Science 295:2250-2253

Fischer-Bruns I, von Storch H, González-Rouco JF, Zorita E (2005) Modelling the variability of midlatitude storm activity on decadal to century time scales. Clim Dyn 21. DOI 10.1007/s00382-005-0036-1

González-Rouco FJ, von Storch H, Zorita E (2003) Deep soil temperature as a proxy for surface temperature in a coupled model simulation of the last thousand years. Geophys Res Lett 30. DOI 10.1029/2003GL018264

Haigh JD (1994) The role of stratospheric ozone in modulating the solar radiative forcing of climate. Nature 370:544546

Hendy EJ, Gagan MK, Alibert MT, McCulloch MT, Lough JM, Isdale PJ (2002) Abrupt decrease in tropical Pacific sea surface salinity at end of Little Ice Age. Science 295:15111514

Hurrell JW (1995) Decadal trends in the North Atlantic oscillation: regional temperatures and precipitation. Science 269:676-679

IPCC (2001) Climate change 2001: the scientific basis. Cambridge University Press, Cambridge. Contribution of working group $i$ to the third assessment report of the Intergovernmental Panel on Climate Change, 881pp
Jakubowski-Tiessen M (1992) Sturmflut 1717: die Bewältigung einer Naturkatastrophe in der Frühen Neuzeit. R. Oldenbourg, München, p 315

Jones PD, Mann ME (2004) Climate over the past millennia Rev Geophys 42(RG2002). DOI 10.1029/2003RG000143

Jones PD, Briffa KR, Barnett TP, Tett SFB (1998) Highresolution paleoclimatic records for the last millennium: interpretation, integration, and comparison with general circulation model control-run temperatures. Holocene 8:455-471

Katz RW, Brown BG (1992) Extreme events in a changing climate- variability is more important than averages. Clim Change 21:289-302

Kharin VV, Zwiers F (2000) Changes in extremes in an ensemble of transient climate simulations with a coupled atmosphereocean GCM. J Clim 13:3760-3788

Kharin VV, Zwiers F (2005) Estimating extremes in transient climate change simulations. J Clim 18:1156-1173

Kiehl JT, Gent PR (2004) The Community Climate System Model, version 2. J Clim 17:3666-3682

Knippert P, Ulbrich U, Speth P (2000) Changing cyclones and surface wind speed over the North Atlantic and Europe in a transient GHG experiment. Clim Res 15:109-122

Lean J, Beer J, Bradley RS (1995) Reconstruction of solar irradiance since 1600: implications for climate change. Geophys Res Lett 22:3195-3198

Leckebusch GC, Ulbrich U (2004) On the relationship between cyclones and extreme windstorm events over Europe under climate change. Global Planet Change 44:181-193

Lindzen RS, Farrell B (1980) A simple approximate result for the maximum growth rate of baroclinic instabilities. J Atmos Sci 37:1648-1654

Lunkeit F, Fraedrich K, Bauer SE (1998) Storm tracks in a warmer climate: sensitivity studies with a simplified global circulation model. Clim Dyn 14:813-826

Luterbacher J, Rickli R, Xoplaki E, Tinguely C, Beck C, Pfister C, Wanner H (2001) The late Maunder Minimum (16751715) - a key period for studying decadal scale climatic change in Europe. Clim Change 49:441-462

Luterbacher J, Xoplaki E, Dietrich D, Rickli R, Jacobeit J, Beck C, Gyalistras D, Schmutz C, Wanner H (2002) Reconstruction of sea level pressure fields over the Eastern North Atlantic and Europe back to 1500. Clim Dyn 18:545-561

Mann ME, Bradley RS, Hughes MK (1999) Northern hemisphere temperatures during the past millennium: inferences, uncertainties, and limitations. Geophys Res Lett 26:759-762

Meehl GA, Zwiers F, Evans J, Knutson T, Mearns L, Whetton P (2000) Trends in extreme weather and climate events: issues related to modeling extremes in projections of future climate change. B Am Meteorol Soc 81:427-436

Pauling A, Luterbacher J, Casty C, Wanner H (2006) 500 years of gridded high-resolution precipitation reconstructions over Europe and the connection to large-scale circulation. Clim Dynam 26:387-405. DOI 10.1007/s00382-005-0090-8

Raible CC, Blender R (2004) Midlatitude cyclonic variability in GCM-simulations with different ocean representations. Clim Dyn 22:239-248

Raible CC, Casty C, Luterbacher J, Pauling A, Esper J, Frank DC, Büntgens U, Roesch AC, Wild M, Tschuck P, Vidale PL, Schär C, Wanner H (2006) Climate variability-observations, reconstructions and model simulations. Clim Change (in press)

Rind D, Shindell DT, Perlwitz J, Lerner J, Lonergan P, Lean J, MacLinden C(2004) The relative importance of solar and anthropogenic forcing of climate change between the Maunder Minimum and the present. J Clim 17:906-929 
Schaeffer M, Selten FM, Opsteegh JD (2005) Shifts of means are not a proxy for changes in extreme winter temperature in climate projections. Clim Dyn 25:51-63

Schär C, Vidale PL, Lüthi D, Häberli C, Liniger MA, Appenzeller C (2004) The role of increasing temperature variability in European summer heatwaves. Nature 427:332-336

Shindell DT, Rind D, Balachandran N, Lean J, Lonergan P (1999) Solar cycle variability, ozone, and climate. Science 284:305-308

Shindell DT, Schmidt GA, Mann MA, Rind D, Waple A (2001) Solar forcing of regional climate change during the Maunder Minimum. Science 294:2149-2152

Sickmöller M, Blender R, Fraedrich K (2000) Observed winter cyclone tracks in the Northern Hemisphere in re-analysed ECMWF data. Q J R Meteorol Soc 126:591-620

Simmons AJ, Gibson JK (2000) The ERA-40 project plan. Technical Report, ECMWF, Shinfield Park, Reading, 63pp

Wajsowicz RC (2002) A modified Sverdrup model of the Atlantic and Caribbean circulation. J Phys Ocean 32:973-993
Yin JH (2005) A consistent poleward shift of storm tracks in simulations of 21st century. Geophys Res Lett 32. DOI 10.1029/2005GL023684

Yoshimori M, Stocker TF, Raible CC, Renold M (2005) Externally-forced and internal variability in ensemble of climate simulations of the Maunder Minimum. J Clim 18:4253-4270

Yoshimori M, Raible CC, Stocker TF, Renold M (2006) On the interpretation of low-latitude hydrological proxy records on Maunder Minimum AOGCM simulations. Clim Dyn. DOI 1007/s00382-006-0144-6

Zorita E, von Storch H, González-Rouco JF, Cubasch U, Luterbacher J, Fischer-Bruns I, Legutke S, Schleese U (2004) Climate evolution in the last five centuries simulated by an atmosphere-ocean model: global temperatures, North Atlantic Oscillation and the late Maunder Minimum. Meteorol Z 13:271-289 